\title{
Pain Passport as a tool to improve analgesic use in children with suspected fractures in emergency departments
}

\author{
Soyun Hwang ${ }^{1, *}$, Yoo Jin Choi $^{3,{ }^{*}}$, Jae Yun Jung ${ }^{1}$, Yeongho Choi ${ }^{1}$, Eun Mi Ham ${ }^{1}$, Joong Wan Park ${ }^{1}$, \\ Hyuksool Kwon ${ }^{2}$, Do Kyun Kim ${ }^{1}$, and Young Ho Kwak ${ }^{1}$
}

'Department of Emergency Medicine, Seoul National University Hospital, Seoul, Korea

${ }^{2}$ Department of Emergency Medicine, Seoul National University Bundang Hospital, Seongnan, Korea

${ }^{3}$ Department of Emergency Medicine, Ajou University Hospital, Suwon, Korea

Received March 30, 2020

Revised July 13, 2020

Accepted July 17, 2020

Handling Editor: Jae Hun Kim

\section{Correspondence}

Jae Yun Jung

Department of Emergency Medicine, Seoul National University Hospital, 101 Daehak-ro, Jongno-gu, Seoul 03080, Korea

Tel: +82-2-2072-3257

Fax: +82-2-741-7855

E-mail: matewoos@gmail.com

*These authors contributed equally to this work.
Background: In the emergency department (ED), adequate pain control is essential for managing patients; however, children with pain are known to receive less analgesia than adults with pain. We introduce the Pain Passport to improve pain management in paediatric patients with suspected fractures in the ED.

Methods: This was a before-and-after study. We reviewed the medical records of paediatric patients who were primarily diagnosed with fractures from May to August 2015. After the introduction of the Pain Passport, eligible children were enrolled from May to August 2016. Demographics, analgesic administration rates, time intervals between ED arrival and analgesic administration, and satisfaction scores were obtained. We compared the analgesic prescription rate between the two periods using multiple logistic regression.

Results: A total of 58 patients were analysed. The baseline characteristics of subjects during the two periods were not significantly different. Before the introduction of the Pain Passport, 9 children (31.0\%) were given analgesics, while after the introduction of the Pain Passport, a significantly higher percentage of patients (24/29, $82.8 \%)$ were treated with analgesics $(P<0.001)$. The median administration times were 112 (interquartile range [IQR], 64-150) minutes in the pre-intervention period and 24 (IQR, 20-74) minutes in the post-intervention period. The median satisfaction score for the post-intervention period was 4 (IQR, 3-5). The adjusted odds ratio for providing analgesics in the post-intervention period was 25.91 (95\% confidence interval, 4.36-154.02).

Conclusions: Patient-centred pain scoring with the Pain Passport improved pain management in patients with suspected fractures in the paediatric ED.

Key Words: Analgesia; Analgesics; Child; Emergency Medical Services; Fractures, Bone; Pain; Pain Management; Standard of Care.

\section{INTRODUCTION}

In the emergency department (ED), adequate pain management is essential; however, children with pain are known to receive less analgesia than adults with pain [1]. The national 2011-2012 College of Emergency Medicine (CEM) audit revealed that pain in children was improperly managed [2], and Drendel et al. [3] reported that the docu- (c) This is an open-access article distributed under the terms of the Creative Commons Attribution Non-Commercial License (http://creativecommons.org/licenses/by-nc/4.0/), which permits unrestricted non-commercial use, distribution, and reproduction in any medium, provided the original work is properly cited.

(C) The Korean Pain Society, 2020
Author contributions: Soyun Hwang Yoo: Writing/manuscript preparation; Jin Choi: Investigation; Jae Yun Jung: Project administration; Yeongho Choi: Formal analysis; Eun Mi Ham: Writing/manuscript preparation; Joong Wan Park: Writing/manuscript preparation; Hyuksool Kwon: Investigation; Do Kyun Kim: Methodology; Young Ho Kwak: Study conception. 
mentation of pain scores in the ED was suboptimal, with younger patients often receiving fewer analgesics than older patients.

Previous efforts were made to improve analgesic administration in the paediatric ED, but the efforts were not successful [4]. The failure was likely because the ED was overcrowded and pain scoring was oriented toward medical personnel rather than toward patients. Since the American College of Emergency Physicians (ACEP) emphasizes the importance of patient- and family-centred care [5], timely management of pain has been designated an important strategy for achieving a patient-centred ED [6].

The "Pain Passport" can serve as a tool for achieving patient-centred pain management. The Pain Passport is a self-reported pain sheet on which the patient or caregiver directly records the degree of pain to help put the child in charge of his or her analgesic needs [7].

In this study, we introduced the Pain Passport to paediatric patients presenting to ED with suspected fractures. The study aimed to evaluate the efficacy of the Pain Passport for improving the analgesic provision rate and time in paediatric patients in the ED.

\section{MATERIALS AND METHODS}

\section{Ethics statement}

This study was approved by the Institutional Review Board (IRB) in Seoul National University Bundang Hospital (IRB No. B-1604/344-006).

\section{Study design}

This investigation was a before-and-after study, conducted at an urban, tertiary teaching hospital. The hospital receives approximately 90,000 ED visits, of which approximately 25,000 are by paediatric patients aged 18 years or younger. The hospital's ED is not a dedicated paediatric ED, but all paediatric patients with chief complaints related to trauma were initially examined by emergency medicine residents under the supervision of board-certified paediatric emergency physicians.

\section{Study populations and settings}

The Pain Passport was introduced and used in the ED from May to August, 2016. During this period (post-intervention period; prospective consecutive period), patients with suspected fractures who presented to the ED were eligible for study inclusion if they were 3 to 18 years old. Patients with chronic illnesses, including congenital malformation, haemato-oncologic malignancy, chronic kidney disease, genetic disorders, allergy to non-steroidal anti-inflammatory drugs (NSAIDs) or opioids, as well as isolated skull and/or facial injury were excluded. The Pain Passport was only written in Korean, so those who were unable to understand the Korean language were also excluded. Research managers or assistants recruited eligible patients from May to August 2016. Patients were enrolled on nonholidays from 1 PM to 9 PM due to researcher availability. We used NSAIDs and opioids for pain management in the study population in accordance with World Health Organization recommendations [8], which are summarized in Supplementary Table 1.

For the controls (pre-intervention group), we reviewed medical records from May to August 2015, before the document was introduced (pre-intervention period; retrospective period), and selected patients in the same age group ( 3 to 18 years old) who had a primary diagnosis of fracture. The exclusion criteria was mostly the same as the post-intervention group. However, as the pre-intervention group did not involve reading and understanding of Korean, we did not try to exclude those who were not able to communicate in the Korean language. Instead, we excluded children with altered mentality, who were unable to communicate. Among the selected patients, final eligibility was determined by the propensity score matching, described in the Statistical Analysis section.

\section{Developing a modified version of the Pain Passport for pain management in the paediatric ED}

A modified version of the Pain Passport was developed based on previous studies. Six paediatric emergency physicians from the paediatric ED met to discuss developing a new version of the Pain Passport suitable for suspected fracture patients.

In a previous study, the Pain Passport consisted of pain scoring explanations (the Wong-Baker Pain Scale [WBPS] and Numeric Rating Scale [NRS]); three boxes to record pain scores three times, including (1) at ED arrival, (2) half an hour after analgesic administration, and (3) upon discharge; and an additional colouring and puzzle page [7]. In our study, the leaflet consisted of four pages, and although only the Korean version of the Pain Passport was used in this study, a translated version of the Pain Passport is shown for readers in Fig. 1. The first page was for the patient's name and identification number, and the second page contained information about the Pain Passport with instructions on when and how to record pain scores. The upper half of the third page explained two pain-scoring methods: the WBPS for 3- to 7-year-olds and the NRS for 

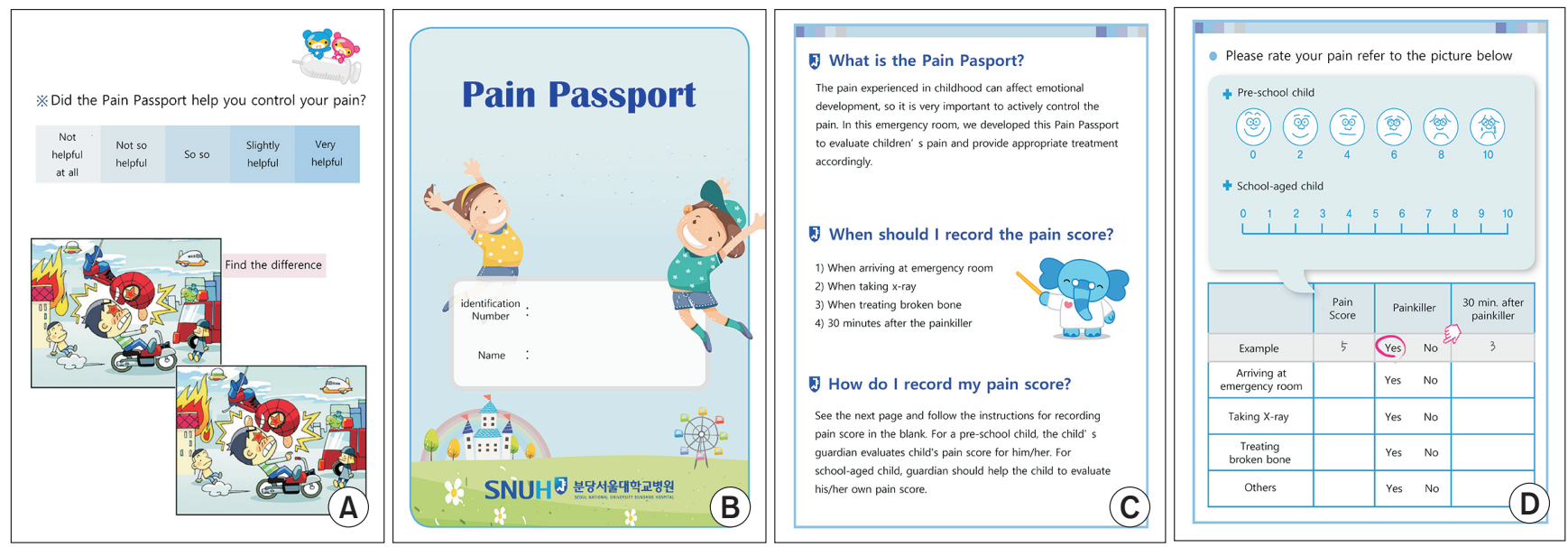

Fig. 1. The Pain Passport used in this study (translated version). (A) The fourth page of the Pain Passport. This page contains a satisfaction survey (5-point Likert scale) and an additional puzzle. (B) The first page of the Pain Passport. This page contains the title and a blank for the patient's name and identification number. (C) The second page of the Pain Passport. This page explains the importance of pain management and the purpose of the Pain Passport; it also contains instructions on when and how to complete the Pain Passport. (D) The third page of the Pain Passport. The upper half of the page explains the two pain scoring methods, the Wong-Baker Pain Scale and Numeric Rating Scale, and the lower half consists of a table to provide the pain score at each time point.

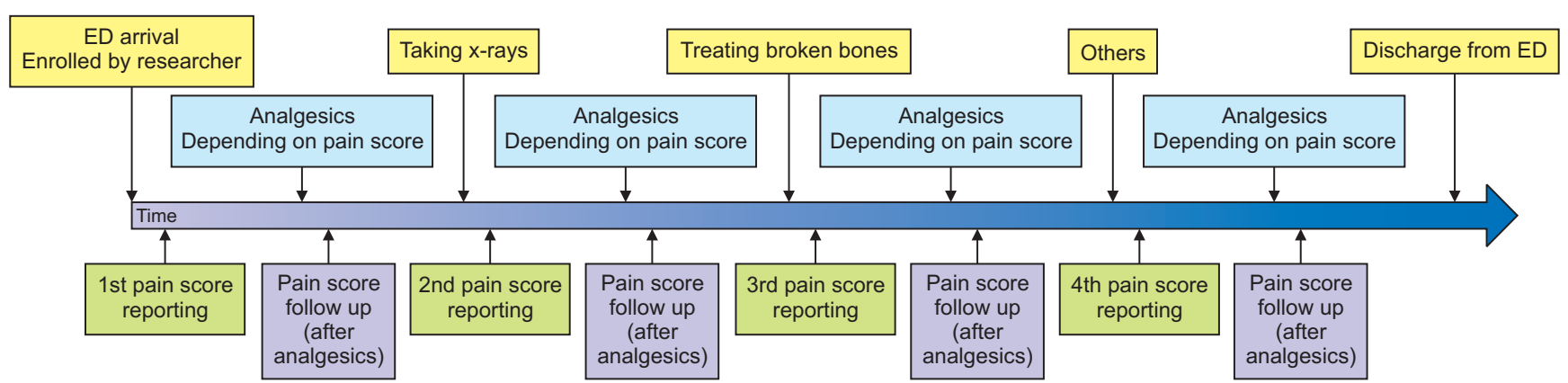

Fig. 2. Timeline of post-intervention period. The pain score was reported by children and/or guardian up to four stages and analgesics was prescribed depending on the reported pain score. Pain score was re-evaluated 30 minutes after analgesics administration. ED: emergency department.

children over 7 years old. The lower half of the third page contained a table for recording pain scores, and the fourth page consisted of the satisfaction survey and an additional children's puzzle. Compared to the previous version, the Pain Passport used in this study measured up to four baseline pain scores and follow-up pain scores for half an hour after analgesic administration. The detailed baseline pain score-recording timepoints are described in the next section.

\section{Study protocol during the post-intervention period}

When a study subject was identified by research personnel, the research personnel gave the Pain Passport to the patient or his/her guardian, obtained informed consent, and educated the patient and guardian on when and how to complete the pain scale. The pain score was recorded with the WBPS (3- to 7-year-olds) or NRS (over 7 years old). Basic demographics (age and sex) and other variables, such as length of ED stay and mechanism of injury were recorded. Pain scores were usually recorded at three to four stages: (1) upon ED arrival, (2) during X-rays, (3) during fracture reduction, and (4) any other additional occasion (Fig. 2).

For each stage, the patient or guardian recorded the pain score at that stage (before analgesics), whether or not the patient received analgesics, and 30 minutes after analgesic administration (if analgesics were administered). At each stage, the patient or guardian reported the pain score to medical personnel (nurse or physician). Treating physicians were strongly encouraged to prescribe analgesics if the enrolled patient's pain score was 4 or above, and they re-evaluated the pain score 30 minutes after analgesic administration. A recommendation guideline for analgesic administration was provided to treating physicians; oral 
NSAIDs (usually ibuprofen) were provided as analgesics for mild pain (WBPS $\leq 4$ or NRS $\leq 5$ points), and an intravenous (IV) opioid (usually fentanyl) was provided for moderate to severe pain (WBPS $\geq 6$ or NRS $\geq 6$ points) (Supplement Table 1). However, because the guideline was not strictly enforced, the treating physician could prescribe other analgesics depending on the circumstance. Moreover, even if the pain score was less than 4 , the treating physician was allowed to prescribe analgesics according to their own medical judgement. In addition, patient and guardian satisfaction was recorded using a 5-point Likert scale at the time of discharge or admission.

\section{Data and outcome measures}

We investigated patients' charts for demographic variables, including age, sex, ED length of stay, pain score at initial presentation (WBPS or NRS), variables associated with analgesics (prescription, type, administration route, and time interval between ED arrival and administration [analgesic administration time] of analgesics), and the mechanism of injury at both periods. The primary outcome was the difference in the analgesic provision rates between the two periods, and the secondary outcomes were the differences in the analgesic administration time between the two periods and patient or guardian satisfaction in the post-intervention period.

\section{Sample size calculation for the post-intervention period}

Researchers conducted a pilot study with a similar study protocol prior to this study in 2013 as a quality improvement campaign in the ED. In the results of the pilot study, the analgesic prescription rate before any intervention was approximately $5 \%$, and the analgesic prescription rate after the introduction of the Pain Passport was approximately $50 \%$, and we assumed $\alpha$ (type I error) was 0.05 and $\beta$ (type II error) minus 1 was 0.8 . Fischer's exact test was used for calculation, the normal-approximation correction for continuity was applied, and the sample size was calculated using STATA version 14.2 (STATA Corp., College Station, TX, USA). The calculated sample size was 15 patients for the post-intervention period, but considering the drop-out rate, which was assumed to be $50 \%$, we planned to enrol at least 30 children for the post-intervention period.

\section{Statistical analysis}

The data were entered into an Microsoft Excel spreadsheet version 16.0 (Microsoft, Redmond, WA, USA) and analysed using R-packages version 4.0.2 (R Foundation for
Statistical Computing, Vienna, Austria), the MatchIt [9] and the cobalt [10] packages. Medians and interquartile ranges (IQRs) were calculated for continuous variables. Proportions were calculated for categorical variables. Differences in categorical variables were assessed using the chi-squared test, and differences in continuous variables were assessed using the Wilcoxon rank-sum test. Twotailed tests were performed with a significance level of 0.05 . Propensity scores were calculated using a probit model to obtain matched pairs of children. We derived a probit model in which the use of the Pain Passport was regressed on age, sex, initial pain score (NRS), and mechanism of injury. With the calculated propensity score, 29 pairs of 1:1 nearest neighbours were matched without calipers. Post-matching balanced statistics were calculated with absolute standardized mean differences, with threshold of 0.1. Univariate logistic regression was conducted for analgesic administration, and multivariate logistic regression adjusted for age, sex, initial pain score, diagnosis category, and injury mechanism was also performed.

\section{RESULTS}

In total, 268 children were eligible in the pre-intervention period, and 218 children were eligible in the post-intervention period. After exclusion, 192 children were left in the pre-intervention period and 30 children were left eligible for propensity score matching. Demographics, pain score, and analgesic administration of the total eligible population are shown in Supplementary Tables 2 and 3. After matching, 29 children in the pre-intervention period and 29 children in the post-intervention period were enrolled for final analysis (Fig. 3). After propensity score matching, demographic characteristics, including age, sex, length of ED stay, the mechanism of injury, and diagnosis category were not significantly different in either period (Table 1), and balanced statistics of covariates are shown in Supplementary Fig. 1.

In the pre-intervention period, 9 of 29 children (31.0\%) received analgesics (Table 2), while 24 of 29 children $(82.8 \%)$ received analgesics in the post-intervention period $(P<0.001)$. The analgesic administration time $(\mathrm{min})$ in the post-intervention period was significantly shorter (24; IQR, 20-74) than in the pre-intervention period (112; IQR, 64150) $(P=0.006)$. The medication type and administration route also differed significantly between the two periods, as shown in Table $2(P=0.028$ and 0.007$)$.

Additionally, we revealed a difference in pain scores before and after administering analgesics (Fig. 4), with a median pain score difference of 3 (IQR, 2-4). The Pain Passport satisfaction score was also recorded (Fig. 5), and 


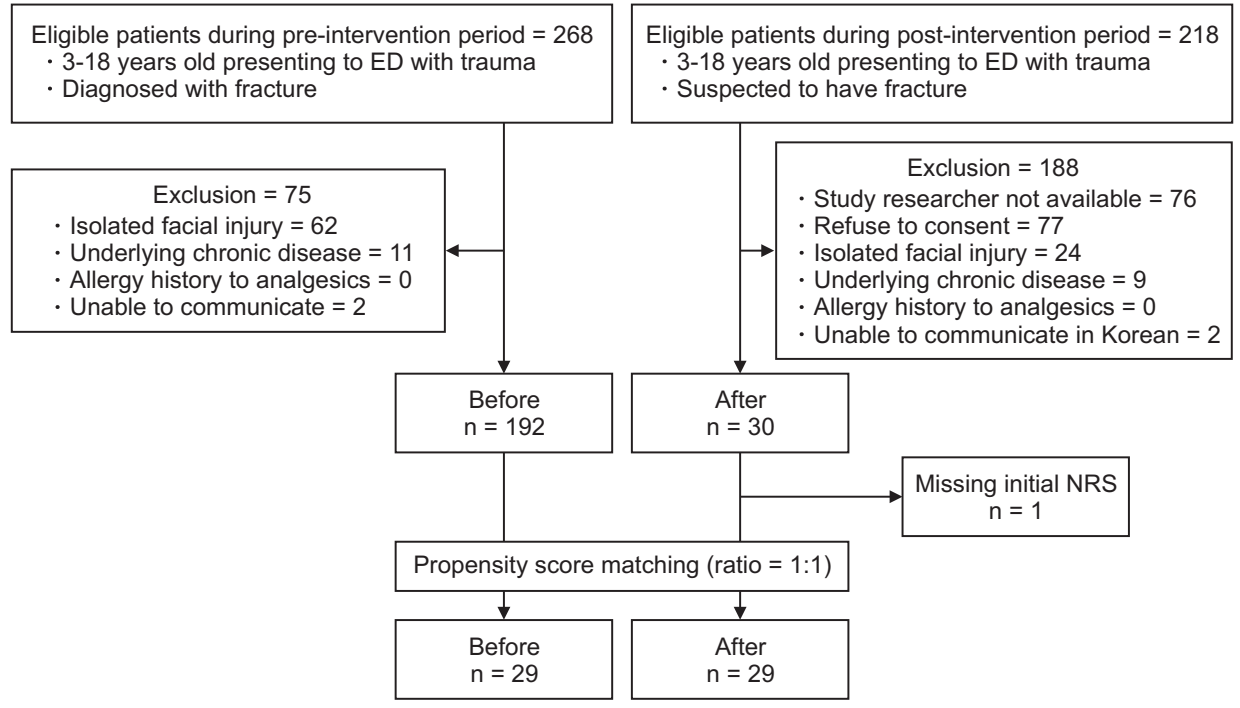

Fig. 3. Flow chart of patients enrolled in this study. ED: emergency department, NRS: Numeric Rating Scale.

Table 1. Patients' Pain Scores and Analgesic Administration

\begin{tabular}{|c|c|c|c|c|}
\hline Variable & Total & Pre-intervention & Post-intervention & $P$ value \\
\hline Total & 58 & $29(50.0)$ & $29(50.0)$ & \\
\hline Male & $46(79.3)$ & $23(75.9)$ & $23(79.3)$ & $>0.99$ \\
\hline Age (yr) & $9(6-12)$ & $9(6-12)$ & $9(6-11)$ & 0.870 \\
\hline ER LOS & $169(121-225)$ & 209 (118-299) & $156(121-187)$ & 0.054 \\
\hline Fractures & $53(91.4)$ & $29(100.0)$ & $24(82.8)$ & 0.061 \\
\hline Injury mechanism & & & & 0.753 \\
\hline Bending, rotating, or compressive forces & $18(31.0)$ & $7(24.1)$ & $11(37.9)$ & \\
\hline Traffic accident & $4(6.9)$ & $2(6.9)$ & $2(6.9)$ & \\
\hline Tripped/slip down & $20(34.5)$ & $10(34.5)$ & $10(34.5)$ & \\
\hline Fall from height & $11(19.0)$ & $7(24.1)$ & $4(13.8)$ & \\
\hline Collision with a stationary object & $5(8.6)$ & $3(10.3)$ & $2(6.9)$ & \\
\hline Unknown & $0(0.0)$ & $0(0.0)$ & $0(0.0)$ & \\
\hline Diagnosis category & & & & 0.489 \\
\hline Rib \& spine & $1(1.7)$ & $1(3.4)$ & $0(0.0)$ & \\
\hline Upper extremity & $44(75.9)$ & $23(79.3)$ & $21(72.4)$ & \\
\hline Lower Extremity & $12(20.7)$ & $5(17.2)$ & 7 (24.1) & \\
\hline Unknown & $1(1.7)$ & $0(0.0)$ & $1(3.4)$ & \\
\hline
\end{tabular}

Values are presented as number (\%) or median (interquartile range).

ER LOS: emergency room length of stay.

the median satisfaction score was 4 (IQR, 3-5). One patient with a low satisfaction score of 1 had an initial pain score of 3 and did not receive analgesics.

The effectiveness of the Pain Passport on analgesic administration using univariate and multivariate logistic regression analyses are shown in Table 3. The odds ratio (OR) for the Pain Passport was 10.67 (95\% confidence interval [CI], 3.08-37.00) in the univariate logistic regression analysis. In the multivariate logistic regression analysis, the OR for the Pain Passport was 25.91 (95\% CI, 4.36-154.02) after adjustment for age, sex, initial pain score, diagnosis category, and injury mechanism.

\section{DISCUSSION}

In previous studies, the analgesic provision rate in the paediatric ED was $52.8 \%$ to $69.3 \%$ in the United States $[3,11]$ but only $13.8 \%$ to $26.8 \%$ in South Korea $[12,13]$. In our study, before the introduction of the Pain Passport, 24.1\% of children received analgesics, which is suboptimal by CEM standards of 50\% within 20 minutes of arrival [14]. After the implementation of the Pain Passport, the analgesic provision rate was $82.8 \%$, an improvement of more than $50 \%$, and the median time to medication was 35.5 minutes, which was also greatly improved by more than 30 minutes. In previous studies performed in South Korea, the an- 
Table 2. Patient's Pain Score and Analgesics Administration

\begin{tabular}{|c|c|c|c|c|}
\hline Variable & Total & Pre-intervention & Post-intervention & $P$ value \\
\hline Total & 58 & $29(50.0)$ & $29(50.0)$ & \\
\hline Initial pain score checked & $58(100.0)$ & $29(100.0)$ & $29(100.0)$ & - \\
\hline Initial pain score & $6(5-7)$ & $6(5-7)$ & $6(5-8)$ & 0.386 \\
\hline Analgesics given & $33(56.9)$ & $9(31.0)$ & $24(82.8)$ & $<0.001$ \\
\hline Time to medication & $64(26-115)$ & $112(64-150)$ & $24(20-74)$ & 0.006 \\
\hline Prescribed medication & & & & 0.028 \\
\hline Paracetamol & $1(3.0)$ & $0(0.0)$ & $1(4.2)$ & \\
\hline Fentanyl & $12(36.4)$ & $4(44.4)$ & $8(33.3)$ & \\
\hline Ibuprofen & $11(33.3)$ & $0(0.0)$ & $11(45.8)$ & \\
\hline Ketorolac & $2(6.1)$ & $2(22.2)$ & $0(0.0)$ & \\
\hline Morphine & $7(21.2)$ & $3(33.3)$ & $4(16.7)$ & \\
\hline Route of medication & & & & 0.007 \\
\hline IV & $20(60.6)$ & $7(77.8)$ & $13(54.2)$ & \\
\hline $\mathrm{PO}$ & $11(33.3)$ & $0(0.0)$ & $11(45.8)$ & \\
\hline Nebulizer & $2(6.1)$ & $2(22.2)$ & $0(0.0)$ & \\
\hline
\end{tabular}

Values are presented as number (\%) or median (interquartile range).

IV: intravenous, PO: per os.

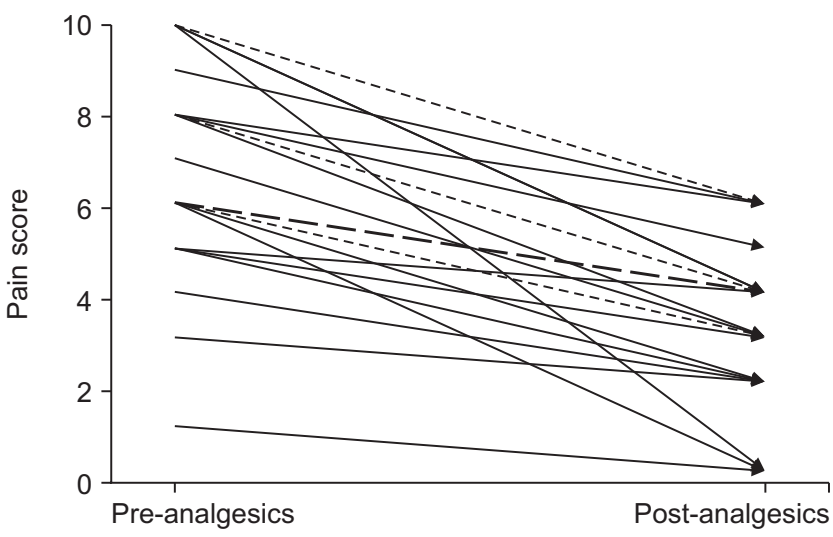

Fig. 4. The change in each patient's pain score before and after the administration of analgesics in post-intervention group. A solid arrow indicates a change in the pain score of a single child, a dotted arrow indicates that there are two children corresponding to the change of the pain score, and a dashed arrow indicates that there are four children corresponding to the change of the pain score.

algesic provision rate was lower than in the United States. This low provision rate may be for many reasons, such as a false belief that children feel less pain than adults, or a lack of experience and familiarity with pain assessment methods and analgesic provision in the paediatric population by ED physicians [12]. In our study, the analgesic provision rate was similar to that of previous studies in the pre-intervention period; however, after the implementation of the Pain Passport, the analgesic provision rate increased significantly. This improvement can be explained by two factors. First, in the busy and crowded ED, medical personnel's ability to assess and manage each patient's pain can be limited and strained. However, patients can record and report their own pain scores to medical per-

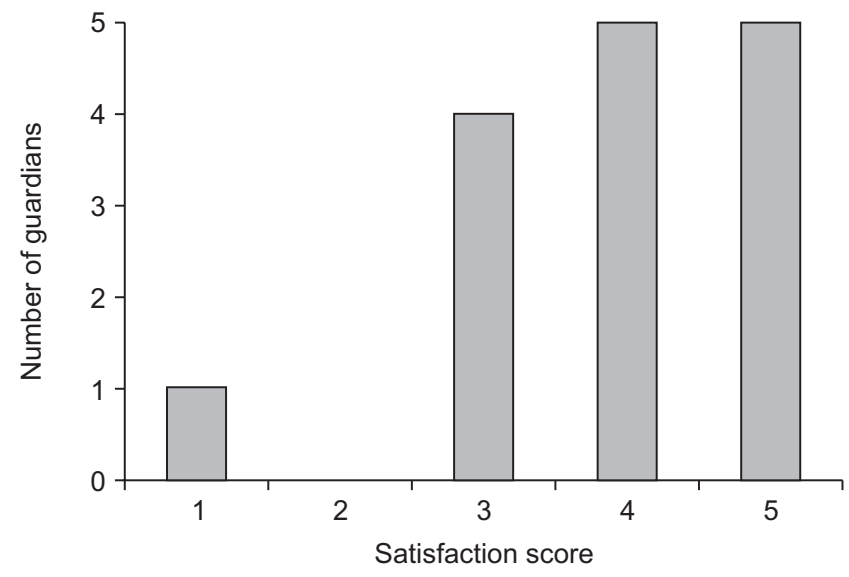

Fig. 5. Distribution of satisfaction scores of the patients and guardians.

sonnel with the Pain Passport, and these records can be a solid basis for administering analgesics. Second, the Pain Passport lets the child assess their own pain intensity and analgesic needs. In previous studies in both ED and nonED settings, when nurses assess children's pain, the pain score tends to be lower than the patient's self-assessed pain score $[15,16]$. However, with the guidance of the Pain Passport, children can report their pain scores quickly and accurately (as they may be higher than before), and analgesics can be administered accordingly.

In addition, the analgesic administration time was shorter after the introduction of the Pain Passport than before. In the pre-intervention period, the mean analgesic administration time was much longer than the CEM standard of 20 minutes ( $65 \mathrm{~min}$; IQR, 58-137 min) [2]. Although the administration time in the post-intervention period still did not meet the CEM standard (24 min; IQR, 20-74 
Table 3. Effectiveness of Pain Passport on Analgesic Administration Using Univariate and Multivariate Logistic Regression Analysis

\begin{tabular}{|c|c|c|c|c|c|c|c|c|c|}
\hline \multirow{3}{*}{ Group } & \multicolumn{2}{|c|}{$\mathrm{N}$} & \multirow{3}{*}{$\%$} & \multicolumn{3}{|c|}{ Unadjusted } & \multicolumn{3}{|c|}{ Adjusted $^{a}$} \\
\hline & \multirow{2}{*}{ Total } & \multirow{2}{*}{ Analgesics } & & \multirow{2}{*}{ OR } & \multicolumn{2}{|c|}{$95 \% \mathrm{Cl}$} & \multirow{2}{*}{ OR } & \multicolumn{2}{|c|}{$95 \% \mathrm{Cl}$} \\
\hline & & & & & Low & High & & Low & High \\
\hline All & 58 & 31 & 53.45 & & & & & & \\
\hline Before & 29 & 7 & 24.14 & 1.0 & & & & & \\
\hline After & 29 & 24 & 82.76 & 10.67 & 3.08 & 37.00 & 25.91 & 4.36 & 154.02 \\
\hline
\end{tabular}

min), it improved greatly compared with that of the preintervention period. The reason for this improvement may be similar to those previously mentioned. Children and parents can record the patients' pain scores at the proper time, and if the pain is severe enough, they can ask the medical personnel immediately for analgesics instead of waiting for nurses to ask about their pain. Additionally, this study was conducted over a relatively short time period of 4 months. If we continued the study and collected more data, further improvement of analgesic administration time could be expected.

Before the matching of the two groups (Supplementary Table 2), the median initial pain score was higher in postintervention group than the pre-intervention group, but we think this difference in the initial pain score is primarily due to two reasons. One reason is that initial pain scores were probably inadequately collected during the preintervention period. Before the introduction of the Pain Passport, the initial pain score was recorded by the triage nurse, but this process was not mandatory. The initial pain score documentation in our study was $51.6 \%$, which is similar to the values found in previous studies conducted in the United States [3]. However, since pain scoring was not a mandatory process, the reliability of the pain scores themselves may have been reduced. Additionally, the pain scorers were different. In the pre-intervention period, the triage nurse assessed the patient's pain; while in the post-intervention period, each patient assessed and reported his/her own pain score with his or her parents. As mentioned previously, in previous studies, nurses using the NRS tended to score patients' pain lower than the patients or their parents did $[15,16]$. Although differences in the initial pain scores may be attributed to differences in pain management processes, the $\mathrm{OR}$ of the multivariate logistic regression analysis, adjusted for the initial pain score, showed that the Pain Passport was associated with a significant improvement in analgesic administration.

The median Pain Passport satisfaction score was 4 (IQR, 3-5), which was higher than the value found in a previous study [17]. Although some studies showed that patient satisfaction was not correlated with pain management or pain score [18], another study, with a more detailed satisfaction survey, found an association between pain management and patient satisfaction [19]. Our study is limited in this aspect because we could not compare satisfaction scores before and after the Pain Passport, but the satisfaction score for the post-intervention period may imply that the patients and/or guardians were satisfied with the Pain Passport.

This study implies that patient-centred pain scoring by the Pain Passport can favourably alter pain management in the ED. Few studies have reported on patient-centred pain scoring, and reporting and understanding the pain experience from the patient's perspective is new [20], thus requiring further research.

Additionally, we primarily used NSAIDs and opioids as analgesics in this study. Gastrointestinal disturbance is an adverse effect of NSAIDs [21], and opioids are known to cause nausea and vomiting and have a sedative effect with short-term use [22]. As previously described, we excluded patients with known allergies to these drugs, and no children reported experiencing these adverse symptoms during our study.

This study had some limitations. First, the children enrolled in the pre-intervention group and the post-intervention group had different inclusion criteria. The children included in the pre-intervention group were those who were diagnosed with fractures, while the children in the post-intervention group were those who had suspected fractures. This was an inevitable limitation since we had to retrospectively review the medical charts of the patients in the pre-intervention group before the study design was even conceived. However, we used propensity score matching to minimize the differences between the two groups. As a result, the two group showed nonsignificant differences in demographics and clinical characteristics, as well as improved covariate balance (Supplementary Fig. 1).

Second, before the Pain Passport, the medical personnel in our hospital knew when and how to prescribe analgesics, but it was not mandatory. Additionally, in the busy atmosphere of the ED, and patient pain being assessed 
by medical personnel, analgesic prescriptions might be lost from time to time. However, after the introduction of the Pain Passport, the medical personnel were informed about the ongoing study, and prescribed analgesics more attentively than before (i.e., the Hawthorne effect).

Third, as this study was not blinded, the patients and guardians may have requested more analgesics than they normally would have. However, our guideline of providing analgesics for pain scores of 4 or higher was not explained to the patients or their guardians, which may have reduced this effect.

Fourth, this study was limited to paediatric fracture patients. Many other causes of pain are seen in the ED, some for reasons other than trauma. Further study including other pain sources should be undertaken. Additionally, this investigation was a single-centre study and involved only 30 patients, which, despite being calculated as an appropriate sample size, seems small. However, the Pain Passport OR was high (25.91 for the adjusted OR), and we think that the Pain Passport's efficacy is strong enough that a subsequent multi-centred study should be considered for further research.

Finally, our study population had a suboptimal basal analgesic provision rate; thus, in EDs that already have good analgesic provision rates, the Pain Passport's efficacy is not guaranteed. However, some EDs still report suboptimal pain management [12]; thus, introducing the Pain Passport may improve pain management in these cases. In conclusion, patient-centred pain scoring using the Pain Passport improves pain management in paediatric fracture patients in EDs.

\section{CONFLICT OF INTEREST}

No potential conflict of interest relevant to this article was reported.

\section{FUNDING}

This research was funded by Department of Emergency Medicine, Seoul National University College of Medicine.

\section{ORCID}

Soyun Hwang, https://orcid.org/0000-0002-4290-0213

Yoo Jin Choi, https://orcid.org/0000-0002-9804-5391

Jae Yun Jung, https://orcid.org/0000-0003-2994-6900

Yeongho Choi, https://orcid.org/0000-0003-3866-1237

Eun Mi Ham, https://orcid.org/0000-0003-4955-5181
Joong Wan Park, https://orcid.org/0000-0002-9702-170X Hyuksool Kwon, https://orcid.org/0000-0002-0960-0198

Do Kyun Kim, https://orcid.org/0000-0002-6144-302X

Young Ho Kwak, https://orcid.org/0000-0003-2062-7575

\section{SUPPLEMENTARY MATERIALS}

Supplementary materials can be found via https://doi. org/10.3344/kjp.2020.33.4.386.

\section{REFERENCES}

1. Petrack EM, Christopher NC, Kriwinsky J. Pain management in the emergency department: patterns of analgesic utilization. Pediatrics 1997; 99: 711-4.

2. The College of Emergency Medicine. Management of pain in children. London, The College of Emergency Medicine. 2013, pp 2-5.

3. Drendel AL, Brousseau DC, Gorelick MH. Pain assessment for pediatric patients in the emergency department. Pediatrics 2006; 117: 1511-8.

4. Jadav MA, Lloyd G, McLauchlan C, Hayes C. Routine pain scoring does not improve analgesia provision for children in the emergency department. Emerg Med J 2009; 26: 695-7.

5. American Academy of Pediatrics Committee on Pediatric Emergency Medicine; American College of Emergency Physicians Pediatric Emergency Medicine Committee, O'Malley P, Brown K, Mace SE. Patient- and family-centered care and the role of the emergency physician providing care to a child in the emergency department. Pediatrics 2006; 118: 2242-4.

6. Saidinejad M. The patient-centered emergency department. Adv Pediatr 2018; 65: 105-20.

7. Newstead BA, Armitage S, Appelboam A. Improving paediatric pain management: introducing the 'Pain Passport'. Emerg Med J 2013; 30: 76-8.

8. World Health Organization. WHO guidelines on the pharmacological treatment of persisting pain in children with medical illnesses. Geneva, World Health Organization. 2012, pp 36-53.

9. Ho D, Imai K, King G, Stuart EA. MatchIt: nonparametric preprocessing for parametric causal inference. J Stat Softw 2011; 42: 1-28.

10. Greifer N. Cobalt: covariate balance tables and plots [Internet]. Version 4.2.3. 2020. Available at: https://CRAN.Rproject.org/package $=$ cobalt.

11. Yackey KJ, Rominger AH. Are we adequately treating pain in children who present to US emergency departments?: factors that contribute to pain treatment in pediatric patients. Pediatr Emerg Care 2018; 34: 42-6.

12. Park SH, Min MK, Ryu JH, Kim YI, Park MR, Park YM, et al. 
Causing factors to determine whether to administer analgesics for patients with isolated long bone fracture in emergency department. J Korean Soc Emerg Med 2014; 25: 363-70.

13. Seo KH, Kim DH, Lee WJ, Woo SH, Seol SH, Lee JY, et al. Factors associated with administration of analgesics for children with forearm fracture. Pediatr Emerg Med J 2017; 4: 758.

14. The Royal College of Emergency Medicine. Management of pain in children. London, Royal College of Emergency Medicine. 2017, pp 8-10.

15. Puntillo K, Neighbor M, O'Neil N, Nixon R. Accuracy of emergency nurses in assessment of patients' pain. Pain Manag Nurs 2003; 4: 171-5.

16. Rajasagaram U, Taylor DM, Braitberg G, Pearsell JP, Capp BA. Paediatric pain assessment: differences between triage nurse, child and parent. J Paediatr Child Health 2009; 45: 199-203.

17. Bhakta HC, Marco CA. Pain management: association with patient satisfaction among emergency department patients. J Emerg Med 2014; 46: 456-64.

18. Todd KH, Sloan EP, Chen C, Eder S, Wamstad K. Survey of pain etiology, management practices and patient satisfaction in two urban emergency departments. CJEM 2002; 4: 252-6.

19. Downey LV, Zun LS. Pain management in the emergency department and its relationship to patient satisfaction. J Emerg Trauma Shock 2010; 3: 326-30.

20. Clapp ADM, Thull-Freedman J, Mitra T, Lethebe BC, Williamson T, Stang AS. Patient-reported pain outcomes for children attending an emergency department with limb injury. Pediatr Emerg Care 2020; 36: 277-82.

21. Tegeder I. NSAIDs, adverse effects. In: Encyclopedia of pain. Edited by Gebhart GF, Schmidt RF. Berlin, Heidelberg, Springer Berlin Heidelberg. 2013, pp 2322-5.

22. Benyamin R, Trescot AM, Datta S, Buenaventura R, Adlaka R, Sehgal N, et al. Opioid complications and side effects. Pain Physician 2008; 11(2 Suppl): S105-20. 